\title{
Modern Basics Philosophy of Education
}

\author{
Oleg Bazaluk¹, Tamara Blazhevich ${ }^{2}$ \\ ${ }^{1}$ Doctor of Philosophy, Professor, Honored Worker of Education of Ukraine, Honorary Member of the Interna- \\ tional Academy of Noosphere (Sustainable Development). The Chairman of the International Society of Phi- \\ losophy and Cosmology (ISPC), the editor-in-chief of the scientific journals Philosophy and Cosmology and Fu- \\ ture Human Image, Kyiv, Ukraine \\ ${ }^{2}$ Kyiv University of Tourism, Economy, and Law, Kyiv, Ukraine \\ Email: bazaluk@ukr.net
}

Received 23 April 2015; accepted 27 June 2015; published 30 June 2015

Copyright (C) 2015 by authors and Scientific Research Publishing Inc.

This work is licensed under the Creative Commons Attribution International License (CC BY). http://creativecommons.org/licenses/by/4.0/

\section{(c) (7) Open Access}

\section{Abstract}

In this article, the authors examine the current understanding of the foundations of the philosophy of education. Lately, when speaking about the human development and education, one concretizes that it is about the perfection of mind. At the end of the XX century, the subject of the educational impact was considered as a person, consisting of social and biological entity, but at the beginning of the XXI century the situation changed. Advances in neurosciences (RistoKalervoNäätänen, James Olds, Donald Olding Hebb, Elhonon Goldberg and others) are allowed to concretize the subject of educational impact and distinguish the material organization in a person that really makes him differ from the world of living organisms. We are talking about neural structures that are formed and developed in the human brain and which are not observed (if they are observed in different formats and with different functional manifestations) in the brain of higher animals. We are talking about consistently evolving neural ensembles of subconsciousness and consciousness which perform the corresponding functions: subconscious (unconscious) and conscious. If the consistent development of the structure of the human brain is studied by neurobiology, the development of the functions of this structure is studied by psychology. Methods, ways and means of transmission of socio-cultural heritage from one generation to another are researched by pedagogy. Therefore, the philosophy of education that considers the impact of educational technology, and global educational model should be based on the integration of research in neurobiology, psychology and pedagogy.

\section{Keywords}

Philosophies of Education, Planetary and Cosmic Personality, Neurobiology, Psychology, Mind 


\section{Introduction}

Lately, when speaking about the human development and education, one concretizes that it is about the perfection of mind. At the end of the XX century, the subject of the educational impact was considered as a person, consisting of social and biological entity, but at the beginning of the XXI century the situation changed. Advances in neurosciences (RistoKalervoNäätänen, James Olds, Donald Olding Hebb, Elhonon Goldberg and others) are allowed to concretize the subject of educational impact and distinguish the material organization in a person that really makes him differ from the world of living organisms. We are talking about the sequentially formed neural structures in the human brain: ensembles of subconsciousness and consciousness (in the terminology of Bekhtereva) (Behtereva, 2008). Formation and development of neural ensembles of subconsciousness and consiousness are observed only in the human brain, and in the brain of mammals; they do not exist.

\section{Neurobiology}

In the authors' understanding, neural ensembles of subconsciousness and consiousness in the Earth have passed a long way of complication: from 5 million years ago till today (Markov, 2011). Each stage of complication it is a new invariant neural hierarchy, including the previous neural structures, as well as new neural education, afferent neurons, sensory neurons, efferent neurons and glial cells. The famous Indian neuroscientist Ramachandran has identified three regions of the brain that exist and actively develop only in the human brain: Wernicke's area is in the left temporal lobe, prefrontal cortex and the inferior parietal lobule in each parietal lobe (Ramachandran, 2012).

The investigation of the features of the development of neural ensembles of subconsciousness and consciousness is studied by such neurosciences as: neurobiology, neuropsychology, neuroanatomy, etc.

\section{Psychology Subject}

Complication of the structure of the human brain led to complication of brain functions. Diversification of manifestation of the human brain functions is being explored by psychology. Psychology is based on studies of neurobiology. Neurobiology for psychology means as much as mathematics for physics. Any manifestations of brain functions follow from the regular development of its structure. Thus, neurobiology studies complication of the structure of neural ensembles of subconsciousness and consciosness, while psychology is examining the emergence and the development of brain functions or the development of mind. In psychology, complex work of neural ensembles of subconsciousness and consciousness is denoted by the concept of "mind", "behavior" and etc. That is why, when talking about the development of mind, we are talking mainly about the three main processes:

1) The natural and a little associated with the environment, actions of genetic programs which are absolutely unknown to modern science, are directionally complicating neural ensembles of subconsciousness and consciousness over time.

2) The natural and associated with the external medium, the development of mind functions. Complication of mind functions directly related to complication of brain structure.

3) The effect of complication of mind functions of the external social environment. The impact of the social environment (along with complication of brain structures) promotes complication of brain function, in particular, the development of genetically predetermined potentials of brain and the completeness of their realization in ontogeny.

Analysis of the psychologists and school psychologists' works in the study of mind functions were written in the article by Bazaluk "Model of Evolution of the Intelligent Matter" (Bazaluk, 2014).

\section{Subject-Specific Pedagogy}

The studies of the features of the environmental influence on complication of mind functions are studied in pedagogy. Except pedagogy, researches of the effect of the environment on complication of mind functions, other scientific disciplines are also involved: sociology, cultural studies, jurisprudence, etc. As for our point of view, namely, pedagogy establishes and sets up the basic ways, methods and means by which the external social environment more fully and effectively affects the manifestations and consolidation of mind functions. As the main external source of complication of mind functions, pedagogy performs the following tasks:

1) Creating favorable conditions for the sequential complication of the structure of neural ensembles of sub- 
consciousness and consciousness, and naturally complication of mind functions.

2) Developing ways, methods and means which due to external shocks provide more full and effective complication of mind functions.

3) Provide transmission of socio-cultural heritage from one generation to another.

4) Adaptation of the developing mind to the conditions of the social environment.

Pedagogy is based on the psychologists' researches and psychological schools. The researches in psychology make the basis of pedagogical models. To organize qualitative and effective impact of the educational process on complication of mind functions it can be only on the basis of knowledge about the stages of complication of the structure and functions of neural ensembles of subconsciousness and consciousness. At the end of the last century Jean Piaget proved that natural complication of the structure and functions of mind is initially, and the influence of the environment, especially at the first stages of the development of the human brain is for the second time (Piaget, 1969).

Thus, we can build a pyramid which shows us the modern understanding of complication of the mind structure and functions in Figure 1.

\section{The Content of Philosophy of Education}

From the point of the authors' view, this pyramid in Figure 1 is nothing else than the content of philosophy of education. Studying and accumulating researches of neuroscience, psychology and pedagogy, philosophy of education explores the technology of forming the human mind. The subject of the researches of philosophy of education is the understanding of complication of the phases of the structure and functions of neural integration of subconsciousness and consciousness. Understanding of the content of this process not only discovers the meaning of the concept of "the most highly developed individual", but also contributes to the formation of technology "the most highly developed mind" (individuals).

The objects of the researches of philosophy of education are educational models-educational technologies on a national scale, aimed at the formation "the most highly developed mind" (individuals).

Philosophy of education on the basis of neurobiological, psychological and pedagogical researches is studying the development of individual technological evolution of "the most highly developed mind", and also technologies on a national scale (national educational systems). It is an interdisciplinary science, in spite of its objectification and practical significance remains relatively connected to specific historical and cultural traditions of the regions. Therefore, among the problems which the philosophy of education has, from the point of the authors' view should be divided into two main tasks:

1. On the basis of modern achievements in neurobiology, psychology and pedagogy, the criteria of an "ideal" personality were formed. In the authors' understanding, it is a planetary and cosmic personality that accumulates a complex of individual characteristics being in demand in scale of the civilization.

2. On the basis of analysis of the existing best education systems in the world, it should be developed the educational technology aimed at forming a planetary-cosmic personality. It is about creating of a universal educational system that is guaranteed to provide qualitative complication of the structure and functions of the individual mind and its adaptation to the specific socio-cultural environment.

\section{A Planetary and Cosmic Personality}

In their researches, the authors develop an understanding of a planetary and cosmic personality and the technology

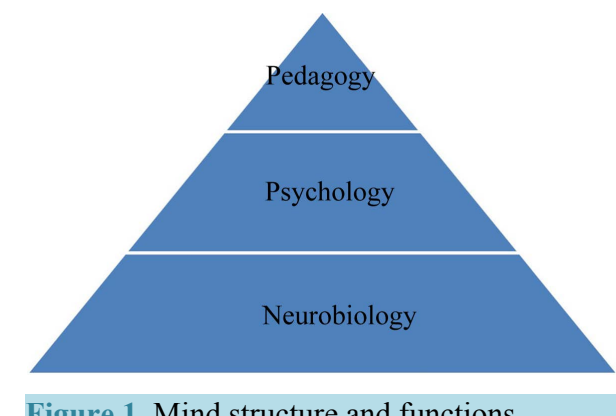

Figure 1. Mind structure and functions. 
for its formation. The authors called the technology of forming of a planetary-cosmic personality, cosmic education. Fundamentals of cosmic education were considered in the article by authors "Cosmic Education: Formation of a Planetary and Cosmic Personality" (Bazaluk \& Blazhevich, 2012).

The authors consider that in the basis of a planetary-cosmic personality, it is mind with dominating work of the neural ensemble of consciousness. Analyses of studies, in the field of neurobiology, psychology and pedagogy, as well as their own researches of the authors, suggest the following conclusions:

1) For objective (hereditary, biological, environmental, etc.) and subjective (inefficiency and backwardness of the educational systems, not professional teachers' training, educational policy states, etc.) reasons, the development of the mind structure and functions in the scale of the civilization is going on unevenly. Modern civilization is represented by mind with different levels of inner perfection. Conventionally, seven billion of minds in the scale of the Earth can be divided into three groups:

a) Minds with the prevailing activity of the neural ensemble of consciousness;

b) Minds, in which the activity of consciousness is slightly inferior to the work of the neural ensemble of subconsciousness;

c) Minds with a distinct work of subconsciousness.

In everyday life dominating work of the neural ensemble of consciousness manifests in more efficient interaction of mind with the information environment. Namely, mind learns more, thinks faster, perceives the problem more scale and chooses the most effective solutions of many options. Mind has exacerbated intuition, is able to think strategically, predicts the future, etc.

The number of the first and the third groups of minds is relatively little and varies within $10-15 \%$ each of the total population. The main group belonged to the second one, minds which balance psy-space of the civilization.

2) The formation of a planetary and cosmic personality is possible on the basis of the vast majority of minds of the modern civilization ( 1 and 2 groups). We are not talking about the loss of national identity and rejection of the cultural values and traditions.

General (universal) characteristics of a planetary and cosmic personality are (Bazaluk, 2010):

-cognitive characteristics: the ability to organize qualified interaction with the external material world; the ability to ask questions and answer them using as much as possible the achievements of modern science and philosophy; to disclose the content of phenomena and processes in the variety of their aspects; to work with qualitative (scientific) information, staking on the content: more scale and deeper knowledge, better and more productive decision will be, etc.

-creativecharacteristics: inspiration, life activity, imagination, flexibility of mind, the ability to find contradiction and depth; freedom of thoughts, feelings and actins; predictability; critically; perseverance in getting aims; having own point of view, etc.

-organizational characteristics: the ability to understand the global purpose in life (which activities, what achievements to devote the most part of ontogeny) and, based on it, to set short-term objectives (e.g. education, family, wealth, career and etc.), to argue the chosen stand in life; to organize consistent achievements of the global purposes through the incarnation of short-term objectives; the ability to plan a daily life; reflective thinking, self-examination, self-control, objective self-evaluation and etc.

-communicative characteristics: make for the need to interact with other people, objects of the material world, the existing information space; the ability to receive, process, keep and transmit information using any available formats; to perform different social roles in a group and staff; to use modern communications technology; to be tolerant, patient; at the same time to be able to forgive and to defend own position, etc.

-worldview characteristics: emotional-valuable attitudes of the subject, determining the ability to self-knowledge and self-perfection, the ability to define a role and a place in the material world, in a family, in the community, in the state; to confirm adherence to universal values and morality, patriotism, honesty, to show loyalty to the ideals; the ability to think tactically (today, tomorrow and the day after tomorrow) and strategic (predictions for decades, for the long term), etc.

\section{Conclusion}

Along with the general characteristics of a planetary and cosmic personality and technology of the formation, there are differences related primarily to the historical and cultural traditions of the region. Formation and development of the most highly developed minds (individuals) and technologies for their creation, which are carried 
out within the limits of the subject and object of the research of philosophy of education, are only possible in a competition and diversity of national education systems. Based on the achievements of neurobiology, psychology, pedagogy and philosophy of education, the people and states of the world create their national education systems, whose effectiveness has been evaluated in the specific socio-cultural environment. The competition of created systems serves for the benefit of the development of the civilization, as it constantly actualizes demands in the scale of the civilization, and personal characteristics and improves the technology of their formation and consolidation in minds.

\section{References}

Bazaluk, O. (2010). Philosophy of Education on Basis of the New Cosmological Concept (458 p). Textbook, Kyiv: Condor.

Bazaluk, O. (2014). The Theory of Evolution: From the Space Vacuum to Neural Ensembles and Moving Forward (312 p). Kyiv: ISPC.

Bazaluk, O., \& Blazhevich, Т. (2012). Cosmic Education: Formation of a Planetary and Cosmic Personality/Философияикосмология/Philosophy \& Cosmology (pp. 147-160). Kiev: ISPC.

Behtereva, N. P. (2008). The Magic of Human Brain and Labyrinths of Life (363 p). Moscow: ACT.

Markov, A. V. (2011). Evolution of Man. Book 2: Monkets, Neurons and Psyche (512 p). Moscow: Astrel: CORPUS.

Piaget, J. (1969). Selected Psychological Works. Psychology of Intelligence. The Genesis of Number in a Child. Logic and Psychology (659 p). Moscow: Prosveshchenie.

Ramachandran, V. (2012). The Tell-Tale Brain: A Neuroscientist's Quest for What Makes Us Human (398 p). Moscow: Kar'era Press. 